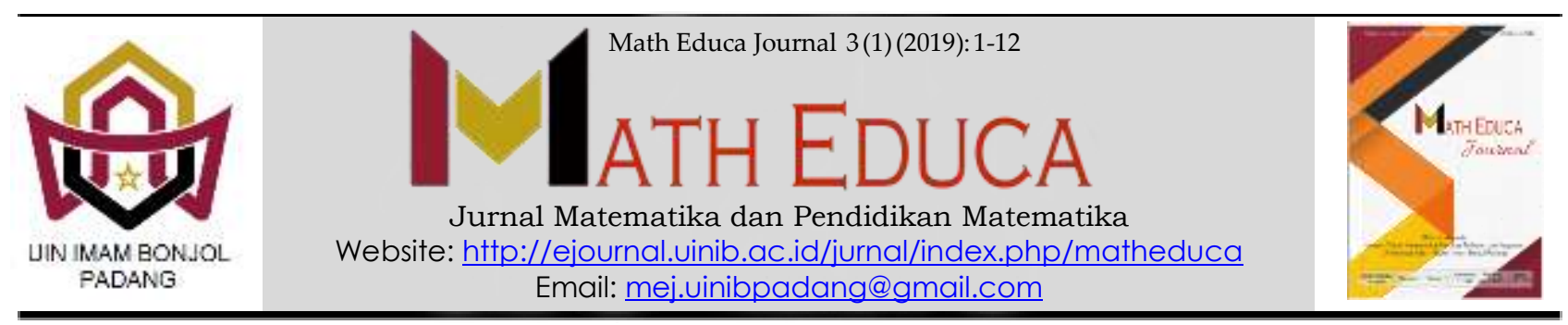

\title{
PENGARUH PERMAINAN KONSTRUKTIF DAN KECERDASAN VISUAL- SPASIAL TERHADAP KEMAMPUAN MATEMATIKA AWAL ANAK USIA DINI
}

\author{
1Jhoni Warmansyah, ${ }^{2}$ Amalina \\ IPendidikan Islam Anak Usia Dini, Fakultas Tarbiyah dan IImu Keguruan, IAIN Batusangkar, Indonesia \\ ${ }^{2}$ Tadris Matematika, Fakultas Tarbiyah dan Keguruan, UIN Imam Bonjol Padang, Indonesia \\ Email: 1 jhoniwarmansyah@iaianbatusangkar.ac.id, ${ }^{2}$ amalina@uinib.ac.id
}

Received: January 2019; Accepted: March 2019; Published: April 2019

\begin{abstract}
Abstrak
Tujuan dari penelitian ini untuk mengetahui pengaruh permainan konstruktif dan kecerdasan visualspasial terhadap kemampuan matematika awal. Pendekatan yang digunakan adalah kuantitatif melalui metode eksperimen dengan desain treatment by level $2 \times 2$. Penelitian ini dilakukan pada anak kelompok B Taman Kanak-kanak di Kota Padang. Teknik pengambilan sampel menggunakan Stratified cluster random sampling. Jumlah sampel dalam penelitian ini sebanyak 40 anak. Pengumpulan data dalam penelitian ini menggunakan tes kemampuan matematika awal dan tes kecerdasan visual spasial. Teknik analisis data dalam penelitian ini menggunakan anava dua jalur untuk melihat efek utama dan interaksi, selanjutnya menggunakan uji Tukey untuk melihat efek sederhana. Hasil penelitian ini adalah sebagai berikut: 1) Anak usia dini dengan diberi perlakukan permainan konstruktif lego memiliki kemampuan matematika awal lebih tinggi dari permainan konstruktif balok ( $\left.F_{\text {hitung }}=5,16>F_{\text {tabe }}(a=0,05)=4,04\right)$. 2) Terdapat interaksi antara permainan konstruktif dengan kecerdasan visual spasial, secara umum berpengaruh signifikan terhadap kemampuan matematika awal anak TK kelompok $B\left(F_{\text {hitung }}=13,34>F_{\text {tabel }(\alpha=0,05)}=4,04\right)$. 3) Anak yang mempunyai kecerdasan visual spasial tinggi, dengan diberi perlakuan permainan konstruktif Lego memiliki kemampuan matematika awal lebih tinggi daripada menggunakan permainan konstruktif Balok $\left.\left(Q_{\text {hitung }}=4,24>Q_{\text {tabel }(a=0,05)}=3,15\right) .4\right)$ Anak yang memiliki kecerdasan visual spasial rendah dengan diberikan permainan konstruktif Balok memiliki kemampuan matematika awal lebih tinggi dari pada diberi perlakuan menggunakan permainan konstruktif lego $\left(Q_{\text {hitung }}=-2,30>Q_{\text {tabel }(\alpha=0,05)}=-3,15\right)$.
\end{abstract}

Kata kunci: Permainan Konstruktif, Kemampuan Visual, Kemampuan Matematika Awal, Anak Usia Dini

\begin{abstract}
The purpose of this study was to determine the effect of constructive play and visual-spatial intelligence on early mathematical abilities. The approach used is quantitative through an experimental method with $2 \times 2$ treatment by level design. This research was conducted on children in kindergarten group $B$ in the city of Padang. The sampling technique uses Stratified cluster random sampling. The number of samples in this study were 40 children. Data collection in this study used an initial mathematical ability test and a spatial visual intelligence test. The data analysis technique in this study used two-way ANOVA to see the main effects and
\end{abstract}

\footnotetext{
*Corresponding author.

Peer review under responsibility UIN Imam Bonjol Padang.

(C) 2019 UIN Imam Bonjol Padang. All rights reserved. 
interactions, then using the Tukey test to see simple effects. The results of this study are as follows: 1) Early mathematical abilities provided with constructive games Lego have a higher influence than constructive games Beams $\left(F_{\text {hitung }}=5,16>F_{\text {tabe }(a=0,05)}=4,04\right) .2$ ) There is an interaction between constructive play and spatial visual intelligence, in general it has a significant effect on the early math skills of kindergarten children in group $\left.B\left(F_{\text {hitung }}=13,34>F_{\text {tabel }}(\alpha=0,05)=4,04\right) .3\right)$ Early mathematical abilities that have high spatial visual intelligence with given constructive games Lego are higher than the initial mathematical abilities with constructive games $\left(Q_{\text {hitung }}=4,24>Q_{\text {tabel }(a=0,05)}=3,15\right)$. 4) Early mathematical abilities that have low spatial visual intelligence with given constructive games Beams have a higher value than the initial mathematical abilities given by constructive games Lego $\left(Q_{\text {hitung }}=-2,30>Q_{\text {tabel }(\alpha=0,05)}=-3,15\right)$.

Keyword: Constructive Games, Visual Ability, Early Mathematical Capabilities, Early Childhood

\section{PENDAHULUAN}

Keterampilan dalam matematika merupakan aspek penting untuk menunjang keberhasilan akademik, ekonomi, dan kehidupan seorang anak. Misalnya, anak yang memiliki keterampilan matematika yang baik memiliki prestasi akademik yang lebih tinggi terkait dengan penyelesaian di perguruan tinggi, pendapatan yang lebih tinggi, dan perawatan kesehatan dibandingkan dengan anak yang memiliki cukup keterampilan (Ritchie \& Bates, 2013).

Usia Taman Kanak-kanak atau dikenal dengan istilah golden age adalah waktu yang tepat untuk menstimulasi pengembangan kognitifnya. Perkembangan kognitif diperlukan oleh setiap anak dalam rangka mengembangkan kemampuan yang diterimanya dari lingkungan. Salah satu aspek penting dalam pengembangan kognitif anak adalah kemampuan matematika awal. Kemampuan matematika awal terkait dengan keterampilan matematika. Secara Teori kemampuan matematika awal setiap individu muncul cukup stabil pada usia prasekolah. Namun dalam kenyataannya tidak sedikit anak yang mengalami kesulitan dalam menguasai keterampilan dalam matematika.

Hal di atas dapat dilihat dari hasil survey yang dilakukan oleh Organization Economic Cooperation and Development (OECD) bernama Program for International Student Assesement (PISA) yang diadakan setiap 3 tahun sekali sejak tahun 2000 mengenai sistem pendidikan dan kemampuan dari siswa sekolah, ternyata Indonesia berada pada peringkat terendah ke-2 dalam bidang ilmu matematika. (Organisation for Economic Co-operation and Development (OECD), 2013).

Berdasarkan hasil observasi lapangan pada beberapa sekolah yaitu TK di Kota Padang, banyak sekali terlihat guru kurang memanfaatkan alat-alat permainan konstruktif untuk meningkatkan keterampilan matematika awal anak. Anak lebih cenderung di fokuskan pada aktivitas calistung yang di ajarkan melalui pemanfaatan Lembar Kerja Anak (LKA). Pembelajaran terlihat monoton karena 
kurangnya stimulasi guru untuk meransang daya berpikir anak sehingga aktivitas pembelajaran terlihat kaku. Hal terburuk dari tindakan tersebut adalah dapat berdampak mematikan daya imajinasi dan kreativitas anak. Media pengenalan pembelajaran matematika awal yang digunakan guru juga kurang bervariasi, sehingga kebanyakan anak terlihat merasa jenuh dan bosan dalam proses pembelajaran di kelas.

Berdasarkan permasalahan di atas diperlukan suatu media pembelajaran konstruktif yang dapat melatih daya imajinasi anak untuk meningkatkan keterampilan matematika awal. Salah satu media pembelajaran konstruktif yang bisa di manfaatkan adalah lego dan balok. Melalui media konstruktif ini anak dapat membangun konstruksi pengetahuan untuk mengenal angka secara konkret melalui warna, melakukan pengukuran dan pengklasifikasian dengan kegiatan bermain. Dengan demikian dapat diasumsikan bahwa bermain konstruktif berpengaruh terhadap kemampuan matematika awal anak.

Hal di atas juga didukung oleh penelitian yang dilakukan oleh (Yelland, 2012) menemukan bahwa permainan diidentifikasi sebagai mekanisme inti dimana anak-anak usia dini berkembang dan belajar. Permainan yang dipandu oleh guru dapat memberikan panduan untuk meningkatkan daya imajinasi anak. Hasil penelitian menunjukkan temuan positif mengenai peningkatan kemampuan matematika awal anak yang diajarkan melalui permainan.

Ada beberapa penelitian yang menganalisis hubungan antara kemampuan konstruksi dan matematika. Sebuah penelitian pada anak usia dini menemukan bahwa membangun model yang sesuai instruksi berkorelasi dengan kemampuan matematika awal pada anak usia 3 tahun (Verdine et al., 2014). Studi lain tentang adaptasi dan kompleksitas permainan konstruksi dan kemampuan matematika awal anak dilakukan dengan mengamati dan merekam permainan konstruksi manipulatif (balok dan Lego) yang dilakukan oleh anak usia 3-4 tahun (Stannard, Wolfgang, Jones, \& Phelps, 2001). Mereka menemukan bahwa korelasi antara permainan konstruksi dan kemampuan matematika signifikan pada tahun awal perkembangan kognitif anak.

Selain itu, salah satu hal yang memberi pengaruh terhadap kemampuan matematika awal anak adalah kecerdasan visual spasial anak. Kecerdasan visual spasial disinyalir sebagai aspek yang dapat memberikan pengaruh terhadap kemampuan matematika awal anak. Menurut beberapa teori, keterampilan spasial penting untuk meningkatkan keterampilan matematika awal siswa karena anak menggunakan keterampilan spasial yang dimiliki untuk menyelesaikan masalah matematika (Caviola, Mammarella, 
Cornoldi, \& Lucangeli, 2012). Ini menunjukkan bahwa komponen yang relevan dari keterampilan spasial untuk meningkatkan pengetahuan matematika akan ditangkap oleh pengetahuan matematika sebelumnya.

Penelitian ini melihat hasil intervensi dari dua permainan konstruktif dalam hal meningkatkan kemampuan matematika awal anak yang dimediasi oleh kecerdasan visual spasial yang dimiliki oleh anak usia dini.

\section{METODE PENELITIAN}

Metode yang digunakan dalam penelitian ini adalah metode eksperimen dengan desain treatment by level $2 \times 2$. Variabel bebas dalam penelitian ini adalah permainan konstruktif $(A)$ yang terdiri dari Lego $\left(A_{1}\right)$ dan balok $\left(A_{2}\right)$, variabel atribut adalah kecerdasan visual spasial yaitu kecerdasan visual spasial tinggi (B1) dan kecerdasan visual spasial rendah (B2). Variabel terikatnya adalah kemampuan matematika awal anak. Adapun konstelasi rancangan penelitian dapat dilihat pada Tabel 1.

\section{Tabel 1. Konstelasi Rancangan Penelitian}

\begin{tabular}{lcc}
\hline \multicolumn{1}{c}{ Konstruktif } & $\begin{array}{c}\text { Permainan } \\
\text { Lego } \\
\left(\mathrm{A}_{1}\right)\end{array}$ & $\begin{array}{c}\text { Permainan } \\
\text { Balok } \\
\left(\mathrm{A}_{2}\right)\end{array}$ \\
$\begin{array}{l}\text { Kecerdasan Visual- } \\
\text { Spasial }\end{array}$ & $\mathrm{A}_{1} \mathrm{~B}_{1}$ & $\mathrm{~A}_{2} \mathrm{~B}_{1}$ \\
\hline $\begin{array}{l}\text { Kecerdasan visual } \\
\text { dan spasial Tinggi }\end{array}$ & & \\
$\begin{array}{l}\left(\mathrm{B}_{1}\right) \\
\text { Kecerdasan visual } \\
\text { dan spasial Rendah }\end{array}$ & $\mathrm{A}_{1} \mathrm{~B}_{2}$ & $\mathrm{~A}_{2} \mathrm{~B}_{2}$ \\
$\left(\mathrm{~B}_{2}\right)$ & & \\
\hline
\end{tabular}

Penelitian ini dilaksanakan di Taman Kanak-kanak Qatrinada dan Taman Kanakkanak Asyofa kecamatan Koto Tangah Kota Padang selama dua bulan. Penelitian dilaksanakan dalam delapan kali pertemuan.

Populasi dalam penelitian ini adalah seluruh siswa kelompok B Taman Kanak-kanak yang berada di kecamatan koto tangah, Kota Padang. Teknik pengambilan sampel dalam penelitian ini menggunakan multi stage random sampling, yaitu dengan memilih secara acak setiap keterwakilan sampel yang ada pada populasi.

Teknik pengumpulan data dilakukan dengan menggunakan pengambilan data secara primer dan sekunder. Data primer adalah data yang diperoleh dari hasil tes yang telah disusun dalam bentuk butir-butir pertanyaan yang berdasarkan indikatorindikator. Data sekunder adalah data yang diperoleh dari dokumen-dokumen atau laporan yang berkaitan erat dengan masalah yang dibahas.

Instrumen dalam penelitian ini mengadobsi dari REMA the Research Based Early Mathematics Assessment berisi subset item dari Penilaian Matematika Awal Berbasis Penelitian (Weiland et al., 2012). Tes ini terdiri dari 19 item, dibagi menjadi dua bagian: 13 item menilai pengetahuan berhitung anak-anak, dan 6 item menilai pengetahuan geometris mereka. 
Instrumen kecerdasan visual spasial menggunakan mengadobsi Desain Blok, subtes dari Wechsler Preschool dan Skala Primer Intelijen - Edisi Keempat (Wechsler, 2012) digunakan untuk mengukur visualisasi spasial. Dalam tes 17-item ini, anak-anak ditunjukkan baik gambar atau model struktur blok dan diminta untuk membuatnya kembali menggunakan blok berwarna merah dan putih. Penilaian diberikan sesuai dengan instruksi standar, dan membutuhkan waktu sekitar sembilan menit untuk diberikan.

Teknik analisis data dalam penelitian ini diuji dengan teknik analisis varian (ANAVA) dua jalur $2 \times 2$. Agar pengujian hipotesis dapat dilaksanakan maka perlu dilakukan uji persyaratan analisis yakni uji normalitas dan uji homogenitas. Uji normalitas dilakukan dengan uji liliefors dan uji homogenitas dilakukan dengan uji barlets. menguji efek utama A dan efek utama $B$, serta pengaruh interaksi antar $A$ dan B (main effect dan interaction effect). Kemudian dilanjutkan dengan uji Tukey untuk menguji perbedaan rata-rata antar sel (simple effect) dan menentukan kelompok yang kemampuan matematikanya lebih tinggi dengan taraf signifikansi $\alpha=0,05$.

\section{HASIL PENELITIAN DAN PEMBAHASAN}

Berdasarkan hasil perhitungan anava yang dilakukan dengan memenuhi prasayat pengujian pada hipotesis, maka diperoleh hasil uji anava 2 jalur seperti pada Tabel 2.
Tabel 2. Hasil Uji Anava 2 jalur

\begin{tabular}{ccccccccc}
\hline \multirow{2}{*}{$\begin{array}{c}\text { Sumber } \\
\text { Variansi }\end{array}$} & Db & JK & RJK & Fhitung & \multicolumn{2}{c}{ Ftabel } & Kesim \\
\cline { 6 - 8 } & & & & $\mathbf{0 . 0 5}$ & $\mathbf{0 . 0 1}$ & pulan \\
\hline Antar A & 66,6 & 1 & 66,6 & 5,16 & $* 4.04$ & 7.19 & $\begin{array}{c}\text { Signifi } \\
\text { kan }\end{array}$ \\
Antar B & 57,5 & 1 & 57,5 & 4,48 & $* 4.04$ & 7.19 & $\begin{array}{c}\text { Signifi } \\
\text { kan }\end{array}$ \\
& & & & & & & \\
$\begin{array}{c}\text { Interaksi } \\
\text { A x B }\end{array}$ & 166,9 & 1 & 166,9 & 13,34 & $* 4.04$ & 7.19 & $\begin{array}{c}\text { Signifi } \\
\text { kan }\end{array}$ \\
$\begin{array}{c}\text { Dalam } \\
\text { Total }\end{array}$ & 461,6 & 36 & 12,82 & & & & \\
\hline
\end{tabular}

Berdasarkan analisis data yang dilakukan dengan melalui proses analisis yang meliputi: a) deskripsi data hasil penelitian, b) pengujian persyaratan uji analisis berupa uji normalitas dan uji homogenitas, uji ANAVA dan uji Tukey. Temuan penelitian tersebut antara lain:

1. Kemampuan matematika awal pada kelompok anak yang diberikan permainan konstruktif Lego lebih tinggi dibandingkan dengan kelompok anak yang diberikan permainan konstruktif Balok

Berdasarkan hasil perhitungan ANAVA terlihat $F_{\text {hitung }}=5,16>F_{\text {tabel }}=4,04$ pada taraf signifikan dengan $\alpha=0.05$, dengan demikian $\mathrm{H}_{\mathrm{o}}$ ditolak dan hipotesis alternatif $\mathrm{H}_{1}$ diterima, artinya hipotesis alternatif yang menyatakan bahwa terdapat perbedaan kemampuan matematika awal antara kelompok anak yang diberikan permainan konstruktif lego dengan kelompok anak yang diberikan permainan konstruktif balok 
diterima. Dengan demikian, perbedaan rata-rata skor kemampuan matematika awal anak yang diberikan permainan konstruktif balok $X=50,0$ lebih tinggi secara nyata dibandingkan kelompok anak yang diberikan metode permainan konstruktif balok $X=47,5$.

Hasil penelitian di atas juga di dukung oleh penelitian yang dilakukan oleh (Nath \& Szücs, 2014) menyatakan bermain konstruksi Lego sangat terkait dengan kinerja matematika pada anakanak dan hubungan ini dimediasi oleh memori visuospatial. Hasil permainan konstruksi dapat secara efektif digunakan untuk melatih dan memperkuat keterampilan matematika pada anak-anak muda dan studi masa depan dapat menyelidiki menggunakan permainan konstruksi untuk remediasi kesulitan belajar matematika tertentu, seperti perkembangan diskalculia.

Sedangkan pada permainan konstruktif balok di prasekolah memberikan konteks di mana anak-anak dapat belajar berbagai keterampilan (misalnya pemecahan masalah, pengambilan perspektif) melalui interaksi mereka dengan balok dan teman sebaya. Terlibat dalam permainan balok memberi anak-anak peluang untuk berpikir dan memahami konsep ruang dan sifat fisik benda (Christakis, Zimmerman, \& Garrison, 2007).

Permainan konstruksi lego dapat menjadikan anak bergerak aktif, dimana kecerdasan anak terbangun melalui rangsangan warna, tekstur, dan bentuk lego yang bervariasi dalam penyelesaian setiap tugas-tugas dalam permainan. Eksperimentasi dalam bermain lego akan merangsang kreatifitas anak melalui rancang bangun baru dan menimbulkan kepuasan anak dalam bermain (Casey, Pezaris, \& Bassi, 2012).

Walaupun kedua permainan konstruksi ini sama-sama dapat meningkatkan kemampuan matematika awal anak akan tetapi dalam hal pelaksanaan dan intervensi yang dilakukan di kedua kelompok eksperimen memeberikan hasil yang berbeda dimana kelompok anak yang diberikan permainan konstruksi lego lebih baik dari permainan konstruksi balok.

\section{Terdapat interaksi antara permainan konstruktif dan kecerdasan visual dan spasial terhadap kemampuan matematika awal (int AxB)}

Hasil perhitungan ANAVA menunjukkan nilai hasil interaksi A X B menunjukkan bahwa Ho ditolak berdasarkan nilai $\mathrm{F}(\mathrm{OAB})=13,34$ dari tabel Daftar-G pada $\mathrm{db}(\mathrm{A}) / \mathrm{db}(\mathrm{D})=1 / 48$ dan $a=0,05$ diketahui Ftab $=4,04$. 
Dikarenakan $\mathrm{F}(\mathrm{OAB})=13,34>\mathrm{Ftab}=4,04$ maka Ho ditolak. Dengan demikian terdapat pengaruh interaksi yang signifikan antara faktor A (permainan konstruktif) dan faktor B (kecerdasan visual spasial) terhadap kemampuan matematika awal anak yang bergantung pada tingkat kecerdasan visual spasial.

Studi menganalisis hubungan antara permainan konstruksi dan kemampuan kognitif telah berfokus pada kecerdasan visual spasial (Robert \& Héroux, 2004). Kecerdasan visual spasial telah dibagi lagi menjadi statis (objek tetap) atau dinamis (Pergerakan objek), dan intrinsik (perbandingan dalam suatu objek) atau ekstrinsik (perbandingan antara objek) (Uttal et al., 2013).

Para peneliti telah lama berpendapat bahwa perbedaan dalam pengalaman spasial awal, seperti bermain konstruktif, dapat berkontribusi pada perbedaan gender dalam keterampilan spasial dan matematika misalnya (Hanline, Milton, \& Phelps, 2010). Keterampilan spasial melibatkan kapasitas individu untuk membandingkan, memanipulasi, dan mengubah informasi visual, nonlinguistik secara manual. Lebih lanjut, peneliti lain juga menemukan bahwa kompetensi bermain konstruktif (balok, lego) pada tugas terstruktur juga memprediksi keterampilan spasial (Robert \& Héroux, 2004).

Hubungan antara keterampilan spasial dan prestasi matematika telah ditunjukkan secara meyakinkan pada tahun-tahun berikutnya di sekolah ketika konten matematika kurang fokus pada pembelajaran numerik, dan pemecahan masalah membutuhkan berbagai strategi solusi (Utami, Qur, \& R, 2008).

Berdasarkan penjelasan di atas maka terdapat interaksi antara kemampuan matematika awal anak dengan permainan konstruktif dan kecerdasan visual spasial anak.

3. Kemampuan matematika awal kelompok anak yang memiliki kecerdasan visual spasial tinggi dan diberikan permainan konstruktif lego lebih tinggi dibandingkan dengan kelompok anak yang memiliki kecerdasan visual spasial tinggi dan diberikan permainan konstruktif Balok

Perhitungan analisis varians tahap lanjut dengan Uji Tukey adalah untuk membandingkan kemampuan matematika awal kelompok yang memiliki kecerdasan visual spasial tinggi yang diberikan permainan konstruktif lego dan yang diberikan permainan konstruktif balok. Maka diperoleh hasil perhitungan nilai Qhitung $\mathrm{A}_{1 \mathrm{~B} 1-\mathrm{A}_{2} \mathrm{~B} 1}=4,24$ $>Q_{\text {tabel }}=3,15$ atau $Q_{\text {hitung }}>Q_{\text {tabel }}$ pada taraf 
signifikan $a=0,05$, dengan demikian $\mathrm{H}_{0}$ ditolak dan hipotesis alternatif $\mathrm{H}_{1}$ diterima. Selain itu, skor rata-rata anak yang memiliki kecerdasan visual spasial tinggi yang diberikan permainan konstruktif lego $X=52,5$ lebih tinggi secara nyata dibandingkan yang diberikan permainan konstruktif balok $X=47,2$.

Anak-anak yang memiliki kemampuan spatial yang tinggi dapat diidentifikasi dari: (a) dapat menggambar-kan ide-ide visual dalam bentuk gambar, (b) dapat memberikan gambaran jelas tentang hal/peristiwa, (c) dapat menggambar sosok orang atau hewan sesuai dengan baik, (d) dapat menyusun pazzel dengan tepat, (e) dapat menyusun balok untuk membangun konstruksi tiga dimensi., (f) mudah memahami gambar dan ilustrasi yang ditampilkan, (Jamaris, 2018).

Hasil penelitian yang dilakukan oleh (Brosnan, 2011) menunjukkan bahwa kemampuan konstruksi Lego berhubungan positif dengan kinerja matematika, dan memori visuospatial sepenuhnya menengahi hubungan ini. Pekerjaan masa depan dari studi intervensi menggunakan pelatihan konstruksi Lego untuk mengembangkan memori visuospatial, yang pada gilirannya dapat meningkatkan kinerja matematika.
Hal di atas juga sejalan dengan penelitian oleh (Wolfgang, 2003) menjelaskan bahawa pada anak usia dini, bermain balok dianggap memberi anak-anak peluang untuk terlibat dalam banyak kegiatan matematika, seperti berhitung, menyortir, mengukur, dan mengklasifikasikan, yang semuanya penting untuk belajar konsep matematika, termasuk keterampilan numerik dan geometri.

Sementara untuk anak spasial tinggi yang diajarkan dengan permainan konstruksi balok terlihat jenuh karena kurang membangun konstruktif dari pengetahuan yang dimiliki oleh anak. Hal ini dikarenakan dalam permainan balok kurang memeberikan variasi dalam hal bentuk atau model alat permaianan yang tersedia, hanya berbentuk balok-balok kayu sehingga daya imajinasi anak untuk membangun pengetahuan yang dimiliki kurang berkembang dengan baik.

Hal ini memberikan gambaran bahwa untuk anak yang memiliki kemamapuan spasial tinggi lebih baik perkembangan kemampuan matematika awalnya bila di ajarkan dengan bermain konstruktif lego. 
4. Kemampuan matematika awal kelompok anak yang memiliki kecerdasan visual spasial rendah yang diberikan permainan konstruktif lego lebih rendah dibandingkan dengan kelompok anak yang memiliki kecerdasan visual spasial rendah yang diberikan permainan konstruktif balok

Berdasarkan hasil perhitungan tahap lanjut dengan Uji Tukey adalah untuk membandingkan kemampuan matematika awal kelompok anak yang memiliki kecerdasan visual spasial rendah yang diberikan permainan konstruktif lego dan balok diperoleh nilai Qhitung A1B2$\mathrm{A}_{2 \mathrm{~B} 2}=-2,30>\mathrm{Q}_{\text {tabel }}=-3,15$ dengan demikian $\mathrm{H}_{\mathrm{o}}$ ditolak dan hipotesis alternatif $\mathrm{H}_{1}$ diterima. Sehingga dapat ditafsirkan tidak dapat perbedaan pengaruh metode pembelajaran yang signifikan. Oleh karena itu, bagi peserta didik yang memiliki kecerdasan visual spasial rendah yang diberikan permainan konstruktif lego $X=47,5$, lebih rendah secara nyata diberikan yang diberikan permainan konstruktif balok $X=47$.

Hasil penelitian ini menemukan bahwa anak yang diajarkan dengan bermain konstruksi balok pada anak yang dengan spasial rendah lebih baik daripada permainan konstruksi lego. Hal ini dikarenakan belajar bermain Balok di prasekolah memberikan konteks di mana anak-anak dapat belajar berbagai keterampilan (mis., pemecahan masalah, pengambilan perspektif) melalui interaksi mereka dengan kedua blok dan teman sebaya. Terlibat dengan balok memberi anak-anak peluang untuk berpikir dan memahami konsep ruang dan sifat fisik benda.

Hal di atas didukung oleh penelitian yang dilakukan oleh (Schmitt, Korucu, Napoli, Bryant, \& Purpura, 2018) menunjukkan bahwa interaksi signifikan ditemukan, untuk berhitung, fleksibilitas kognitif, dan fungsi eksekutif global, anak-anak dari orang tua dengan tingkat pendidikan yang rendah mendapat manfaat paling banyak dari partisipasi intervensi. Temuan ini memberikan bukti awal untuk efektivitas intervensi bermain blok semi-terstruktur dalam meningkatkan kesiapan sekolah anakanak dan memiliki implikasi untuk memasukkan instruksi yang disengaja menggunakan blok di ruang kelas prasekolah.

Penelitian lain juga menunjukkan bahwa kompleksitas bermain balok terkait dengan keterampilan matematika awal (Trawick-Smith et al., 2016) dan bahwa kinerja bermain blok awal dikaitkan dengan kemudian skor matematika standar (Wolfgang et al., 2001). Selanjutnya, kemampuan anakanak muda untuk menyelesaikan tugas merakit balok yang saling terkait 
merupakan prediksi kinerja matematika jangka pendek dan jangka panjang.

Dengan demikian untuk anak yang memiliki kecerdasan visual spasial rendah, meningkatkan kemampuan matematika awal dapat dikembangkan dengan baik menggunakan permainan konstruksi balok.

\section{SIMPULAN DAN SARAN}

\section{Simpulan}

Berdasarkan hasil penelitian dan pembahasan penelitian maka di peroleh kesimpulan sebagai berikut:

1. Kemampuan matematika awal anak usia dini dapat dikembangkan diantaranya dengan memperhatikan kecerdasan visual spasial anak dan menggunakan permainan konstruktif.

2. Permainan konstruktif yang dapat diterapkan pada anak usia dini diantaranya adalah permainan konstruktif lego dan balok.

3. Secara umum kemampuan matematika awal anak usia dini yang di berikan dengan permainan konstruktif lego berpengaruh lebih tinggi daripada permainan konstruktif balok.

4. Pengoptimalan kemampuan matematika awal anak usia dini dengan kecerdasan visual spasial tinggi dapat dilakukan dengan permainan konstruktif lego.
5. Pengoptimalan

kemampuan matematika awal anak usia dini dengan kecerdasan visual spasial tinggi dapat dilakukan dengan permainan konstruktif balok.

\section{Saran}

Setelah mengetahui hasil penelitian ini bagaimana efektifitas permainan konstruktif baik Lego maupun Balok, para pendidik hendaknya mengajarkan kedua permainan konstruktif ini kepada peserta didik dalam meningkatkan kemampuan matematika awal anak serta melihat faktor lain yang memberi pengaruh terhadap kemampuan matematika awal anak seperti kecerdasan visual dan spasial yang dimiliki peserta didik. Mengingat pentingnya hal tersebut, orang tua juga bisa membantu dirumah dengan menemani anak bermain konstruktif bersama agar perkemabangan matematika awal anak berkembang dengan optimal untuk menunjang kesiapan sekolah anak pada pendidikan selanjutnya.

\section{REFERENSI}

Brosnan, M. J. (2011). Spatial Ability in Children's Play with Lego Blocks. Perceptual and Motor Skills, 87(1), 19-28. 
Casey, B. M., Pezaris, E. E., \& Bassi, J. (2012). Adolescent boys' and girls' block constructions differ in structural balance: A block-building characteristic related to math achievement. Learning and Individual Differences, 22(1), 25-36.

Caviola, S., Mammarella, I. C., Cornoldi, C., \& Lucangeli, D. (2012). The involvement of working memory in children's exact and approximate mental addition. Journal of Experimental Child Psychology, 112(2), 141160.

Christakis, D. A., Zimmerman, F. J., \& Garrison, M. M. (2007). Effect of Block Play on Language Acquisition and Attention in Toddlers. Archives of Pediatrics \& Adolescent Medicine, 161(10), 967.

Hanline, M. F., Milton, S., \& Phelps, P. C. (2010). The relationship between preschool block play and reading and maths abilities in early elementary school: A longitudinal study of children with and without disabilities. Early Child Development and Care, 180(8), 1005-1017.

Jamaris, M. (2018). Pengembangan Instrumen Baku Kecerdasan Jamak Anak Usia Dini. PARAMETER: Jurnal Pendidikan Universitas Negeri Jakarta, 25(2), 123-137.

Nath, S., \& Szücs, D. (2014). Construction play and cognitive skills associated with the development of mathematical abilities in 7-year-old children. Learning and Instruction, 32, 73-80.

Organisation for Economic Co-operation and Development (OECD). (2013). PISA 2012 Assessment and Analytical Framework: Mathematics, Reading, Science, Problem Solving and Financial Literacy. OECD Report.
Ritchie, S. J., \& Bates, T. C. (2013). Enduring Links From Childhood Mathematics and Reading Achievement to Adult Socioeconomic Status. Psychological Science, 24(7), 1301-1308.

Robert, M., \& Héroux, G. (2004). Visuo-spatial play experience: Forerunner of visuospatial achievement in preadolescent and adolescent boys and girls? Infant and Child Development, 13(1), 49-78.

Schmitt, S. A., Korucu, I., Napoli, A. R., Bryant, L. M., \& Purpura, D. J. (2018). Using block play to enhance preschool children's mathematics and executive functioning: A randomized controlled trial. Early Childhood Research Quarterly, 44, 181-191.

Stannard, L., Wolfgang, C. H., Jones, I., \& Phelps, P. (2001). A longitudinal study of the predictive relations among construction play and mathematical achievement. Early Child Development and Care, 167(1), 115-125.

Utami, S., Qur, N., \& R, E. K. (2008). Playing Lego Increase Cognitive Development on Preschool Child ( 4-5 Years Old ). Keperawatan.

Verdine, B. N., Golinkoff, R. M., Hirsh-Pasek, K., Newcombe, N. S., Filipowicz, A. T., \& Chang, A. (2014). Deconstructing Building Blocks: Preschoolers' Spatial Assembly Performance Relates to Early Mathematical Skills. Child Development, 85(3), 1062-1076.

Wechsler, D. (2012). Wechsler preschool and primary scale of intelligence-fourth edition. Encyclopedia of Autism Spectrum Disorders, 3400-3400. 
Weiland, C., Wolfe, C. B., Hurwitz, M. D., Clements, D. H., Sarama, J. H., \& Yoshikawa, H. (2012). Early mathematics assessment: Validation of the short form of a prekindergarten and kindergarten mathematics measure. Educational Psychology, 32(3), 311-333.
Wolfgang. (2003). Advanced constructional play with LEGOs among preschoolers as a predictor of later school achievement in mathematics. Early Child Development and Care. https://doi.org/http://dx.doi.

Yelland. (2012). Australasian Journal of Early Childhood. 37.2 FIVE, 36(2). 